\title{
Erratum to: Omeprazole Absorption and Fasting Gastrinemia After Roux-en-Y Gastric Bypass
}

\author{
Renata V. A. Collares-Pelizaro ${ }^{1}$ - José S. Santos ${ }^{1}$ - Carla B. Nonino ${ }^{2}$. \\ Cristiane M. Gaitani ${ }^{3} \cdot$ Wilson Salgado $\mathbf{J r}^{1}$
}

Published online: 24 August 2017

(C) Springer Science+Business Media, LLC 2017

Erratum to: OBES SURG (2017) 27:2303-2307

https://doi.org/10.1007/s11695-017-2672-z

The authors omitted their funding sources. The following statement should be added to the Acknowledgments section: Financial support was received from FAEPA- Fundação de Apoio ao Ensino, Pesquisa e Assistência do Hospital das Clínicas da Faculdade de Medicina de Ribeirão Preto da Universidade de São Paulo; Fundação Waldemar Barnsley Pessoa, Hospital São Francisco Ribeirão Preto, SP; and CNPq -National Research Council / Conselho Nacional de Pesquisa.

The online version of the original article can be found at https://doi. org/10.1007/s11695-017-2672-z

Wilson Salgado, Jr

wsalgado@fmrp.usp.br

Renata V. A. Collares-Pelizaro

renatacollares@usp.br

José S. Santos

jsdsanto@ fmrp.usp.br

Carla B. Nonino

carla@fmrp.usp.br

Cristiane M. Gaitani

crisgai@ fcfrp.usp.br

1 Department of Surgery and Anatomy, Clinical Hospital, Faculty of Medicine, University of São Paulo, Ribeirão Preto, Brazil

2 Department of Clinical Analysis, Toxicology and Bromatology, Faculty of Pharmaceutical Sciences, University of São Paulo, Ribeirão Preto, Brazil

3 Nutritional Division of the Department of Medical Clinic, Clinical Hospital, Faculty of Medicine, University of São Paulo, Ribeirão Preto, Brazil 